\title{
EDITORIAL: \\ The Impact of Socio-Economic, Cultural, Political, and International Factors on Latinos/Latinas in United States
}

\section{Irene Queiro-Tajalli Special Issue Editor}

This special issue has the potential to make substantive contributions to the existing literature on Latinos. The issue presents the assets, challenges, and opportunities Latinos face in this country. It also highlights the impact that the quality of the socio-politicaleconomic Latin America-United States relations has on this population. It contributes to the discourse on Latinos in areas of interest to social workers and other human services providers and offers an understanding of the Latino experience in this country.

We are mindful that the use of the terms Spanish, Latinos, Hispanics, or country of origin may express different personal, political, or governmental views. Therefore, the choice was left to the contributors to select the terminology used to represent the population they addressed. As an immigrant from Argentina, I was first classified as a Hispanic. Then the 2000 census gave me the choice to check the Spanish/Hispanic/Latino box, however, when I travel to Central and South American countries, I am an Argentinean. It is no wonder that "who am I" has been the subject of attention by Latino authors for many years.

Latinos are the fastest growing population in the United States due to immigration and high birth rates, two factors that are dramatically changing the diversity composition in this country. An important aspect of this population is that Latinos have lived on parts of this land since colonial times while others are recent immigrants. The challenges, needs, and the means by which they identify with Latin America vary greatly, indeed, intra-group differences are many. As a result, the authors have avoided generalizations by focusing on particular groups and the specific generations the immigrants represent.

In this special issue, we want to emphasize the fact that large numbers of Latinos are impacted by events in Latin America, as well as by the U.S. government's position on immigration and foreign policies toward Latin America. An example of the serious nature of the disagreements between the Latin American countries and the United States was reflected in the discouraging outcome of the 2012 Summit of the Americas (a gathering of the heads of state of the countries of the Americas) when the United States opposed the acceptance of Cuba to the next Summit meeting. Another example is the neutral position taken by the United States on the long-standing conflict between Argentina and England regarding the sovereignty of Las Islas Malvinas (Falkland Islands). The lack of U.S. solidarity with Latin American countries is a critical issue, particularly when there is an emerging move among Latin American countries to seek trade agreements and other

\footnotetext{
Irene Queiro-Tajalli, Ph.D., is a Professor and Chair of the Department of Labor Studies in the Indiana University School of Social Work. Professor Queiro-Tajalli would like to express her appreciation for the important contributions made by Craig Campbell, MSW, Department of Labor Studies Student Services Coordinator, who was like a co-editor through the process of compiling and assembling this issue.
}

Copyright (C) 2013 Advances in Social Work Vol. 14 No. 1 (Spring 2013), i-viii 
collaborative enterprises with nontraditional international partners, particularly those in the Middle East, East and South Asia.

It is beyond the scope of this issue to thoroughly address the debate over immigration from Latin America, or attempt to answer the perennial questions of "Do undocumented workers take jobs from residents?” "Do they lower wages?” "Why don’t they stay home?" Yet the issues are woven in several of the articles. And indeed, these writings try to give a human face to Latinos and their efforts to be part of this country. To add a personal touch to this editorial, I would like to share one of my experiences as an immigrant. Years ago, a colleague and I were conducting a training session on diversity for human services providers. As I was presenting on the struggles of Latino immigrants trying to survive on this land, one of the participants bluntly asked me, "If you do not like it here, why don't you go back to your country?” The remark has kept me wondering to this day, who is serving our most vulnerable populations?

As the reader will notice, finding adequate employment to support a family, obtaining educational and social services, maintaining a sense of well-being, and living a healthy lifestyle all depend on gaining access to the larger society and being surrounded by a nurturing environment of acceptance and connectedness within the larger community. Humans acting as cultural liaisons can provide ample transitional benefits to immigrants. It is through human connections that Latino students experience mentoring and tutoring, which helps them succeed in the American school system, that parents learn how to support their children entering college as first generation students, that graduating Latino social workers find support in locating suitable employment, that workers unite to find a common empowering voice, that minors find a voice in the child welfare system, that policymakers understand the real impact of emerging immigrant legislation, and that vibrant communities are built and sustained for the benefit and well-being of their members. Our connections with others define our lives and help bring direction and focus when things are not clear. Helping others succeed in life is deeply rooted in the social work profession and is practiced on a daily basis. Unlocking the door to cultural acceptance and holding it open for the next generation is one of the ways that social workers can promote the well-being of Latinos in the United States. This issue draws from practitioners and educators well versed on a wide range of current Latino topics to enhance our understanding about this complex population group. I anticipate it will motivate others to continue the critical discussion about the challenges faced by Latinos in the United States and the impact events occurring in Latin America have on them. I hope that the seventeen articles included in this issue add to the knowledge base on the Latino population and encourage our readers to further explore the assets, challenges and opportunities of this population. I would also like to extend sincere thanks to the authors for selecting Advances to share their knowledge and scholarly work, our devoted reviewers, and Dr. Bill Barton for his ongoing assistance with this project.

The following summaries for this introduction are organized by subject matter.

\section{Latin American Activism}

While organized labor is under attack in the United States, it is refreshing to read about a Brazilian approach to labor education based on the tenets advanced by Paulo 
Freire. "Workers, Education, and Social Change in Brazil” by William Mello examines the influence of educational programs organized by social movements and labor organizations in Brazil. The article looks at new ways to conscientize workers based on Freire's pedagogical approach. Programs like Projeto Integrar, organized by the National Confederation of Metalworkers, seek to expand the political and social consciousness of workers to help them understand their roles as actors in a democracy. Furthermore, the project provides education to strengthen future generations of working class activists for the purpose of sociopolitical transformation that supports working class political influence in society and increases labor's role in deciding public policy issues. The conclusion highlights the pivotal role of unions in advancing the cause of workers in specific trades and their organized efforts to support the plight of other popular movements. This reading also reminds us how easy it is to lose ground on labor achievements given a growing international neoliberal agenda.

In "Globalization, Inequality, and Transnational Activism: A Case Study on Chile," Moctezuma Garcia examines the influence that globalization has had on reinforcing inequality and transnational activism. It also brings to the forefront the dark history of that country during the government of Pinochet. The author suggests that Chile be considered a model for activists in understanding how to coordinate initiatives that hold local governments accountable. This historical perspective on Chile highlights how economic, political, and social events influenced the development of a nation. A section on transnational activism provides a useful model for social workers who want to mobilize efforts, locally as well as abroad, to advocate for highly vulnerable populations.

\section{The Effects of Acculturation and Cultural Integration on Well-being}

In "Colombians in the United States: A Study of Their Well-Being," Cándida Madrigal examines the effects of four factors: acculturation, ethnic identity, self-esteem, and resilience among immigrants in the United States, specifically Colombians, to understand which factors contribute to overall well-being. In controlled studies of three waves of Colombian immigrants, Madrigal explores the reasons for leaving Colombia, to better understand the relationship between the overall climate of the receiving country and the immigrant's sense of well-being. The results of the study indicated that a strong ethnic identity negatively predicted well-being for all participants in the sample. Consequently, as the extent of ethnic identity increased, well-being decreased. In contrast, Madrigal's study revealed that high self-esteem, obtained by feeling integrated into the receiving culture, correlated with and predicted higher levels of well-being. Madrigal concludes that while Latinos share many characteristics, there are great variations in responses according to the country of birth and reasons behind immigration. Therefore, it is necessary to examine, treat, and study Latino cultures individually and not as a collective group.

The process of acculturation may cause conflict within individuals and families who experience competing pressures in adopting new cultural norms and maintaining cultural traditions. The connection between life satisfaction and successful integration into a new culture, which includes employment, stability of familial relationships, and community roles are explored in "Acculturation and Life Satisfaction Among Immigrant Mexican 
Adults.” Flavio F. Marsiglia, Jaime M. Booth, Adrienne Baldwin, and Stephanie Ayers address the impact of acculturation and familismo on reported life satisfaction and resilience among Mexican American adults living in the Southwest, many of whom are immigrants. Marsiglia et al. sampled Latino/a parents of seventh grade students enrolled in American educational institutions to help identify predictors of general life satisfaction, resilience, familism, and acculturation. Their findings indicate that individuals with a bilingual orientation report significantly higher levels of life satisfaction and resilience than their strictly Spanish-speaking counterparts. Therefore, creating spaces that facilitate multicultural identities for Mexican immigrants, in both social work practice as well as the larger society, may be crucial to promoting a quality mental health system for populations that face stressors in the process of acculturation.

\section{Understanding Health Issues Affecting Latino Populations and Quality of Life}

In "Addressing Older Latinos' Spiritual Needs in Hospital Settings: Identifying Predictors of Satisfaction,” David R. Hodge, Robert J. Wolosin, and Robin P. Bonifas sought to identify the factors likely to determine older Latinos' satisfaction with the process that health care workers employ when addressing their spiritual needs during hospitalization. Hodge et al. point out the need for health care providers to feel comfortable discussing the spiritual needs of the Latino patients, if that is of importance to them. The authors contend that spirituality needs to be a consideration in all the

processes of the hospitalization experience. Social workers are considered instrumental in addressing patients' spirituality while going through treatment and at time of discharge. The authors propose the inclusion of content on spirituality, including spiritual assessment, in the training of social workers and other human services providers.

In "Quality of Life of Latina Breast Cancer Survivors: From Silence to Empowerment,” Gloria P. Martinez-Ramos, Mary Jo Garcia Biggs, and Yvonne Lozano interviewed long-term Latina breast cancer survivors to understand the effects of the cancer experience on the women, their families, and their communities. The authors skillfully give a voice to the survivors concerning their experiences, challenges, fears, and courage through an empowering dialogue between interviewer and interviewee. The authors asked the tough and sensitive questions of living as a cancer survivor as well as the "positive" effects of such a diagnosis. Fears and concerns about femininity, roles, and relationships, as well as a lack of support from the health care system are some of the challenges expressed by the women. Martinez-Ramos et al. found that Latinas who found appropriate support among their communities often became stronger as a result and saw themselves more capable of helping others in similar circumstances. This manuscript provides rich content for social workers concerning their interventions with cancer survivors and it highlights the importance of advocating for culturally sensitive health care options and post operative support. The authors provide recommendations for practice at the individual, family, and community levels. They call for creativity when developing resources for the Latina breast cancer survivors and their families. 


\section{Educational Attainment Opportunities}

In "Leadership Development for Latino Community Emancipation: An Integrative Approach in Social Work Education," authors Antonia Elizabeth Cordero and Lirio K. Negroni outline the importance of leadership development within the social work community, and in Latino communities in particular. The authors assert that strong leadership is needed in and among the Latino communities as a response to a history of encountered invisibility, oppression and discrimination in the United States; and their struggle to achieve fair treatment and emancipation. They highlight the Latino Project at the New England School of Social Work as a model to demonstrate how higher education promotes leadership and acts as a springboard toward the acquisition of effective leadership skills. Cordero and Negroni note that sustained institutional commitments in the form of support and resources; the creation of leadership opportunities that include mentoring and modeling; and leadership efforts for community emancipation must coincide to create a collective, culturally-attuned, and transformative leadership process that will prepare individuals and groups to lead collectively with others whose cultures and practices differ from their own.

In search of "what works," Sarah P. Maxwell considers what parental or familyrelated factors contribute to Latino youth enrolling in four-year post-secondary institutions, where future earnings tend to be higher than two-year colleges with fewer opportunities. In "Parental and Familial Factors Among Latino/a Youths' Successful Matriculation into Post-Secondary Education,” Maxwell uses Critical Race Theory to examine the strong influence that Latino families have in affecting the choices made by degree-seeking Latinos. Although discrimination is certainly a factor in the ongoing gap between what Latinos can achieve educationally and what they do achieve, it is not the leading impediment to attaining an education. Maxwell found that beliefs and the subsequent actions that affirm the importance of education play a much larger role in determining students' educational abilities. Family dining, parental educational attainment, parental participation and involvement in academic preparation combined can improve a Latino youth's potential success in attaining higher education. Among other findings, the article underscores the importance of understanding the relationship between the realities of daily living and the limited availability of parents to have quality meeting times with teachers. The author also highlights the importance of schools showing flexibility to accommodate the families' realities. Understanding the complexities of bringing innovation to the public school system, the author calls for gradual innovations at the local level.

Even when Latino students successfully attain and complete degree programs in the United States, their options for employment can be limited by their lack of employment resources and access to the professional networks crucial to finding quality employment opportunities. Nelly Rojas Schwan, Lirio K. Negroni, and Annette Santiago-Kozmon, in "Culturally-Attuned Mentoring for Graduating Latina/o Social Workers to Foster Career Advancement," present an innovative mentoring program for Latina/o social work professionals conceptualized and led by the Latina/o Network of the Connecticut chapter

of the National Association of Social Workers. Schwan et al., in studying the benefits of mentoring Latino college students, found that culturally-attuned mentoring, attained by 
connecting students with mentors who share similar cultural backgrounds, works by taking advantage of common cultural values to build relationships that foster trust and acceptance. Culturally-attuned mentoring helps students become bicultural, that is, to maintain their Latino culture and function successfully within the educational institutional environment, a process that allows them to develop resources to improve their chances of employment.

In "Reducing Barriers to Career Entry for Latinos: An Examination of Pathways into Social Work," Anthony De Jesús describes program models that seek to address obstacles to Latinos' successful entry into social work careers. The study analyzes the program components of three career pathway initiatives focused on supporting Latinos in enrolling and completing two- and four-year undergraduate and graduate degrees in social work. Areas of need identified by the programs for Latino adults include tuition support, academic support, and other support services to students. Key program components offered by these models include academic advising, language proficiency assistance, positive student-faculty relations, and mentoring and tutoring geared toward addressing the specific academic needs of Latino students. The author concludes that career pathways create potential for Latinos who are already employed in social work fields, but who have not completed their undergraduate or graduate social work degrees. He points out the dual opportunity of helping Latinos complete their degrees to better serve both the Latino and the general communities.

In "The Role of Acculturation in the Civic Engagement of Latino Immigrants," Cristina Michele Tucker and Anna Maria Santiago conducted focus groups and utilized data from the Latino National Survey (2006) to examine how variations in levels of multidimensional acculturation, demographic characteristics, socioeconomic status, and characteristics of the immigrant experience might influence the civic engagement of Latino immigrants in American society. Specifically, Tucker and Santiago found that citizenship, English language proficiency, length of residence in the United States, and higher socioeconomic status enhanced civic engagement, while brown skin color, migration for economic reasons, and Mexican ancestry decreased participation. Understanding the impact that various factors have on an immigrant's integration into the political landscape may improve initiatives that seek to enhance Latino cultural experiences and enrich the quality of life in Latino communities.

\section{Impacts of Immigration Legislation}

Cecilia Ayón and David Becerra consider the impact that all forms of discrimination have on Mexican American families living in Arizona. In "Mexican Immigrant Families Under Siege: The Impact of Anti-immigrant Policies, Discrimination, and the Economic Crisis," the authors assert that in the wake of recently passed legislation targeting undocumented immigrants in Arizona, institutional and horizontal discrimination, as well as micro-aggressions, place Latino immigrants (both documented and undocumented) at greater risk for lower educational attainment, higher rates of unemployment, family disintegration, reduced access to healthcare, lowered social participation, and higher rates of antisocial behavior, stress, and depression. 
Sylvia Romero and Melissa Romero Williams examine recent immigration legislation in order to highlight the detrimental effects that laws designed to enforce national immigration policy can have on immigrant families living in the United States. In "The Impact of Immigration Legislation on Latino Families: Implications for Social Work," Romero and Romero Williams address the effects of racial profiling and the targeting of undocumented immigrants in Latin American communities. The authors emphasize the ways in which Latin American children who are born in the United States suffer as a result of the detention and deportation of their parents. The authors conclude with a discussion of the components of the Dream Act, prosecutorial discretion, immigrants as job creators and tax contributors, and the implications for social work practice, education, research, and for policy.

\section{Navigating Economic and Employment Challenges}

Resilience is measured in one's ability to navigate not only the normative social structures, but also to invent new methods of survival apart from established social constructs. In "Social Networks That Promote Well-Being Among Latino Migrant Day Laborers,” Nalini Junko Negi, Lynn Michalopoulos, Javier Boyas, and Adrianna Overdorff explore the social service and public health needs of a high risk sub-population of immigrants comprised mainly of single, young, Latino transmigrant men who travel back and forth across the Mexican/American border in search of informal economic opportunities as day laborers. These Latino day laborers (LDLs) are generally employed in construction or demolition work and are often at risk for exploitation and worker's rights abuses, including wage theft and dangerous working conditions. Their vulnerability is heightened due to their undocumented immigration status, and as such, they are considered easily deportable and beyond the protection of the law. The authors found that the LDLs in this study used their social networks, particularly those developed with their peers at the day labor corner, as well as with families, employers, and church members to improve their well-being, which is seriously compromised due to their precarious conditions, lack of service use options, and fear of the police. The authors highlight the need for integrating the voices of LDLs when planning for social services and advocating for the human rights of this vulnerable population.

Many recent Latino immigrants have found employment in North Carolina's agricultural and construction-related job sector. The increase in labor-driven transnational migration is often attributed to the economic restructuring of the region. Lisa de Saxe Zerden, Arianna Taboada, and Quentin Joshua Hinson explore the inherent implications of racially segregated labor in "Carolina del Norte and the New South: Social Work Practice with New Latino Immigrant Communities.” The authors found that despite the active recruitment of Latino/Latina workers by select industries, the local reception of immigrants has been fraught with anxiety, fear, acculturative stress, and larger sociopolitical challenges. Specifically, the authors highlight key social demographics of Latino populations, as well as theoretical concepts and methodological issues related to the complex needs of this diverse population group. Zerden et al. offer an overview of social workers engaging with immigrant communities and argue that the profession brings strengths and unique knowledge, value, and skills to address the needs of Latinos 
in the South. At the same time, the authors highlight the need to develop multi-level interventions that indicate a thorough understanding of the local and global issues affecting Latino immigrant groups.

\section{Puerto Rican Perspectives}

The graying of the population is a phenomenon that, although foreseen by scientists and policy makers for several decades, reveals that the degree of preparedness for this population shift varies from country to country. In "Family Assistance for Older Adults in Puerto Rico,” Paul-Jesús Fericelli discusses a progressive government legislation that aims at safeguarding the wellbeing of the elderly with the support of relatives and significant others and applying fiscal responsibility at a time of dwindling resources. The author examines The Act for the Improvement of the Family Assistance and for the Support of the Elderly, Act No. 193 of 2002, based on the values of fairness, familism, fraternity, and accountability, indeed, four fundamental values of the Latino culture. The Act also prescribes the processes involved in case the caregivers do not fulfill their responsibilities.

This journal issue concludes with an article in Spanish, "Voces de los Menores Inmigrantes en el Sistema de Cuidado Sustituto de Puerto Rico.” In this article Evelyza Crespo-Rivera gives voice to immigrant minors who are under the custody of the government of the Estado Libre Asociado de Puerto Rico. Through the review of agency records and personal interviews with the minors, the author constructs the immigrant experience and compares their treatment to that of the statutes that establish the protection, security, quality of life, and nondiscrimination of minors. Crespo-Rivera concludes that the minors themselves are an important source of information for practitioners interested in grasping the realities of the lives of displaced minors, which in her study includes a perceived lack of support from the receiving country, as well as human services organizations, and a unanimous outcry for the system to respond to their needs. Crespo-Rivera found an undeniable need for closer supervision of the foster homes, more dialogue with the minors during home visits, and more culturally-sensitive training for foster families. She also recommended that in the future, immigrants who were under the custody of the state as a minor be part of advisory committees, interdisciplinary groups, and help integrate evaluation teams of child welfare organizations.

\section{Author note:}

Address correspondence to Irene Queiro-Tajalli, Ph.D., Indiana University School of Social Work, Department of Labor Studies, 902 W. New York St., Indianapolis, IN 46202-5156. E-mail: itka100@iupui.edu 